\title{
Factors associated with moderate to high nicotine dependence in a sample of pregnant women from Romania
}

\author{
Marina Denisa Dascăl ${ }^{123}$, Cristian Ioan Meghea ${ }^{2,3,4}$, Priyanka Dubey ${ }^{5} \&$ Adriana Băban $^{1}$ \\ ${ }^{1}$ Department of Psychology, Babeș-Bolyai University, Cluj-Napoca, Romania \\ ${ }^{2}$ Center for Health Policy and Public Health, College of Political, Administrative and Communication Sciences, Babeș- \\ Bolyai University Cluj-Napoca, Romania \\ ${ }^{3}$ Department of Public Health, College of Political, Administrative and Communication Sciences, Babeș-Bolyai University \\ Cluj-Napoca, Romania \\ 4 Department of Obstetrics, Gynecology and Reproductive Biology, College of Human Medicine, Michigan State University, \\ USA \\ ${ }^{5}$ College of Public Health, University of Iowa, USA
}

Received 18.09.2019; Received revised 3.12.2019; Accepted 12.12.2019

Available online 31.12.2019

\begin{abstract}
The objective of this paper was to identify the factors associated with moderate to high nicotine dependence in a sample of pregnant smokers from Romania. Data was collected through an ongoing cross-sectional pilot study from 130 pregnant smokers. The questionnaire included five main sections: socio-demographic information, medical and reproductive history, alcohol and smoking behaviors, emotional health and information regarding the relationship with the partner. Older age, first pregnancy, a negative screening for anxiety and depression, and negative partner interactions related to smoking were significantly correlated with increased odds of moderate to high nicotine dependence during pregnancy. In addition, high dyadic efficacy, low self-efficacy, high pregnancy-related anxiety, and a non-smoking life partner were correlated with increased odds of moderate to high nicotine dependence, although the results did not reach statistical significance. Once the level nicotine dependence is established, cessation treatment should target specific risks that are associated with this dependence. Maternal risk factors, spousal smoking status, and interactions in the couple hold promise in future tobacco cessation interventions. Future research should focus on both the prenatal smoking cessation and on postnatal relapse prevention among highly dependent women.
\end{abstract}

Keywords: nicotine dependence, pregnancy, risk factors, smoking, Romania

Address of correspondence: Marina Denisa Dascăl, 7 Pandurilor Street. Cluj-Napoca, Romania, 400376

E-mail: dascalmarinadenisa@gmail.com.

\section{Introduction}

Smoking during pregnancy is identified in many countries as the most important preventable risk factor for adverse pregnancy and birth outcomes (Cnattingius, 2004). Smoking during pregnancy is still prevalent in many populations and some studies suggest that the continuous smokers during pregnancy may be the most addicted and find it the most difficult to quit (Melvin \& Gaffney, 2004). Smoking increases risk of various obstetric complications such as preterm rupture of the membrane, premature delivery, incompetent cervix and pregnancy induced hypertension. (Hayashi, Matsuda, Kawamichi, Shiozaki, \& Saito, 2011). In order to avoid these morbidities and mortalities among the infant and the mother, smoking cessation support is needed by pregnant smokers. Smoking cessation during pregnancy is one of the most effective ways of preventing poor birth outcomes such as intrauterine growth restriction which may lead to pre-term birth or low birth weight, sudden infant death syndrome, decreased pulmonary function, increased risk for respiratory tract infection, neurobehavioral disorders, 
malformation of mouth and lip and triggering pathogenesis of fetal and childhood onset of adult diseases, particularly pulmonary and cardiovascular diseases (Mund, Louwen, Klingelhoefer, \& Gerber, 2013; Ko et al., 2014; DiFranza \& Lew, 1995; Little, Cardy, \& Munger, 2004).

Tobacco smoking among women in Romania increased dramatically, by close to $30 \%$ between $2011-2018$, and the share of smokers with quit attempts decreased by $37 \%$. Approximately (Ministerul Sanatatii, 2018) 28\% of the pregnant women in Romania were smokers 6 months before pregnancy and $15 \%$ of pregnant women continue to smoke during pregnancy (Meghea, Rus, Rus, Summers Holtrop, \& Roman, 2012; Blaga, Branzaniuc, Rus, Chereches, \& Wallis, 2016). Pregnant women in Romania and women living in other low-income or middle-income countries report increased smoking rates before and during pregnancy and lack smoking cessation and prevention programs tailored to pregnancy and postpartum (Meghea et al., 2018). Although no tobacco consumption level is considered safe for the fetus, a higher smoking intensity, calculated through the number of cigarettes smoked per day, is associated with more severe effects on the fetus compared to smoking less frequently (Curtin \& Mathews, 2016a). One important and crucial factor in establishing likelihood of cessation success during pregnancy smoking is nicotine dependence (Panaretto et al., 2009). Nicotine dependence refers to individuals who are smoking regularly and become chronically dependent to nicotine (Tsai, Edens, \& Rosenheck, 2011).

Factors associated with nicotine dependence during pregnancy are: aged under 25 years old, low level of education, unmarried and living in extended families (Nur, 2017). A systematic review reported similar findings where women of younger age, have low social status, a large number of children, without a partner or living with a partner who smokes, and deficient prenatal care, are more likely to smoke than other women (Schneider \& Schütz, 2008). Other risk factors for maternal smoking imply poor coping skills, heavy smoking (>10cigarettes per day), public insurance and emotional or psychiatric problems such as generalized anxiety disorder, bipolar disorder, drug abuse or dependence, and attention deficit-hyperactivity disorder (Flick et al., 2006; Rodriguez, 2019). Pre-natal smoking was also associated with lack of ante-natal care, non-attendance of ante-natal classes, (Schneider \& Schütz, 2008; Mohsin \& Bauman, 2005a) unintended pregnancy (Hellerstedt et al., 2011; Meghea, Rus, \& Rus, 2012a; Nur \& Nur, 2017; Širvinskienè et al., 2016), and early or single motherhood (Nur, 2017; Graham, Hawkins, \& Law, 2010).

Additionally, a study based in Romania indicate that pregnant smokers with nicotine dependence were more likely to have had depressive symptoms, carried an unwanted pregnancy, and consumed alcohol during pregnancy (Meghea, Rus, \& Rus, 2012b). Another study reports similar findings where smoking during pregnancy was significantly associated with prenatal alcohol consumption, previous elective abortion, and lack of positive emotional acceptance of pregnancy by mother, education, and family structure (Širvinskienè et al., 2016).

There is a critical need to better understand the most addicted pregnant smokers, as cessation may be less likely among these women and more effective cessation interventions are needed for pregnant smokers. Interventions for smoking cessation should be addressed as early as possible to women who smoke during pregnancy and offer them adequate help and resources to quit smoking (Samet, Yoon, \& World Health Organization,
2010). Pregnancy can be considered as a window of opportunity to involve health professionals to get involved in offering smoking cessation support (Passey, SansonFisher, D'Este, \& Stirling, 2014).

The objective of the research paper was to identify the factors associated with moderate to high nicotine dependence in a sample of pregnant smokers from Romania. The contribution of this paper is to investigate the associations of risk factors previously not researched, including partner smoking, relationship variables, and other characteristics (e.g. pregnancy-related anxiety, general self-esteem) with moderate-to-high nicotine dependence during pregnancy.

\section{Materials and methods}

\section{Study design}

Data was collected through an ongoing cross-sectional pilot study from 130 smoker pregnant women.

\section{Participants}

The total number of participants was 130 . The mean age of the participants was $28.85(\mathrm{SD}=6.18)$ and the range was 40 . The eligibility criteria for inclusion in the research project were being aged over 18 years old, being pregnant and being a smoker.

\section{Study setting and data collection}

During November 2018 to the end of May 2019, pregnant women were enrolled from online groups, forums, online pages or websites focused on pregnancy through weekly posts about the subject of the research project and the link of the online survey. Before completing the questionnaire, the participant had to answer to the eligibility questions and if eligible they were asked to read and fill an informed consent if they were interested to take part in the study.

\section{Measures}

The questionnaire included five main sections: sociodemographic information, medical and reproductive history, alcohol and smoking behaviors, emotional health and information regarding the relationship with the partner.

The outcome: Nicotine Dependence. The Heaviness of Smoking Index (HSI) is a standard brief, validated, and widely used measure of nicotine dependence (Borland, Yong, O'Connor, Hyland, \& Thompson, 2010; Heatherton, Kozlowski, Frecker, Rickert, \& Robinson, 1989; John et al., 2004). It is calculated based on two items from the Fagerström Test for Nicotine Dependence, which is a standard instrument used in evaluating the intensity of physical addiction to nicotine (Heatherton, Kozlowski, Frecker, \& Fagerström, 1991). HSI was frequently used in a high number or nicotine dependence focused research studies among pregnancy (Chaiton, Cohen, McDonald, \& Bondy, 2007; Panaretto et al., 2009). The first HSI item relates to the timing of smoking initiation after waking up in the morning. This item has the following categories: in the first 5 minutes, after 5-30 minutes, after 31-60 minutes, and after more than 60 minutes. The second HSI item refers to the quantity of cigarettes smoked in a given day, this item's categories range from 10 cigarettes or less, 1120 cigarettes, 21-30 cigarettes, 31 or more cigarettes. The two items were summed up together, the score being categorized in low nicotine dependence (0-1), moderate nicotine dependence (2-4), and high nicotine dependence (5-6) (Heatherton, Kozlowski, Frecker, Rickert, Robinson, 
1989). The two items used in the Heaviness of Smoking Index (HSI) based on the Fagerstorm test were found to account for most of the prediction value of the Fagerstrom questionnaire and were validated as providing similar results (Etter, Duc, \& Perneger, 1999; Heatherton, Kozlowski, Frecker, \& Fagerström, 1991). The standard HIS scoring sums the two items and categorizes nicotine dependence as low (0-1), moderate (2-4), or high (5-6) (Heatherton et al., 1989). We dichotomized the outcome into moderate-high and low nicotine dependence for our analysis.

Socio-demographic variables. Age categories were defined as $<25$ years old, 26-30 years old, and $>31$ years old. The level of education was coded binary as high school or less vs college or more. Furthermore, household income was coded binary as less than 3000 RON $(<633.57 €)$ vs $>=3001$ RON $(>=633.78 €)$. We also assessed first pregnancy and this indicator was coded binary: 1 if the current pregnancy was the first vs 0 otherwise. Marital status also was recoded binary as married and not married but living with a partner. Initially, partners of participants were identified as being a smoker, being an ex-smoker, or never been a smoker. This was later recoded as a dichotomous variable (smoker vs. nonsmoker).

Pregnancy-Related Anxiety. In order to identify levels of anxiety during pregnancy, an adapted version of the Pregnancy-Related Anxiety Questionnaire-Revised (Huizink, Mulder, Robles De Medina, Visser, \& Buitelaar, 2004) was administered. This instrument consists of 10 items that focus on feelings and expectations about the birth and the child. The following are examples of statements participants responded to: 'I think my labor and delivery will go normally', 'I am fearful regarding the health of my baby', 'I am worried that the baby might not be normal', and 'I am afraid that I will be harmed during delivery'. The statements were answered with a 4-point Likert scale ranging from ' 1 - Not at all', ' 2 - Somewhat, ' 3 - Moderately', and ' 4 - Very much'. The scores for each question were added into a sum and higher scores were interpreted as having higher anxiety levels. Using the median, we dichotomized the pregnancy-related anxiety score into low and high.

Self-efficacy. Self-efficacy was measured with Schwarzer's and Jerusalem's General Self-Efficacy Scale' (GSE) (Schwarzer \& Jerusalem, 1995). The GSE involves 10 items and asks participants to answer each question using a 4-point Likert Scale. The scale consists of '1 Never, '2 - Hardly true', '3 - Moderately true', and '4 Exactly true'. The GSE items refer to how confident one feels they could solve difficult issues, how well one deals with unexpected events, how resourceful one feels, and how well one copes and remains calm when faced with difficult situations and other items. The total score was found by adding the scores for each item with possible scores ranging from 10 to 40 . A higher total score indicated increased self-efficacy. Based on the median, the variable was dichotomized in two different categories, low and high self-efficacy score.

Anxiety and Depressive symptoms. 'Patient Health Questionnaire-4' (PHQ-4) was used to investigate if respondents had any symptoms for anxiety and depression (Kroenke, Spitzer, Williams, \& Lowe, 2009). This questionnaire has 4 items which assessed during the last two weeks the frequency of when women felt nervous or anxious, unable to control their worrying, not having interest or feelings of enjoyment doing things, and when they felt depressed or helpless. Answers were expressed on a 4-point Likert scale ranging from not at all, several days, more than half of the days, and nearly every day. The items' scores were summed up for a total score then categorized into normal (0-2), mild (3-5), and moderate to high (6-12) anxiety and depression symptoms.

Dyadic Efficacy. For measuring dyadic efficacy (Sterba et al., 2011a) pregnant women were asked to answer on 8 items on a scale from 0 to $100(0=$ not at all confident, $100=$ very confident) how confident they feel that they could work with their partner together in multiple smoking-related situations such as dealing together with ups and downs of trying to quit, focus on the benefits of quitting smoking, deal with different negative emotions experienced when trying to quit and other items. The answers for all items were averaged and a score was generated. The score was divided in two categories based on the median, low dyadic efficacy vs high dyadic efficacy.

Teamwork Standards, Furthermore, for teamwork standards (Sterba et al., 2011b) we used a scale from 1 to 10 measuring to what extent the women think that the problems related to smoking cessation should be managed alone or with the help of their partner (1= manage them alone, $10=$ manage them together).

Partner Interaction. Partner interaction was measured through three items focusing on positive partner behaviors and three negative partner behaviors related to the woman's tobacco cessation (Cohen \& Lichtenstein, 1990). The positive items were that the partner expressed confidence in her ability to quit or remain quit, congratulated her for the choice of quitting smoking and expressed pleasure in her attempts to give up smoking. The negative items were that the partner convinced her to stop smoking a cigarette, and made remarks that smoking is a bad habit and Likert scale options were "Never", "Almost never", "Sometimes", "Fairly often" and "Very often". We calculated separate scores for positive and negative partner interactions measured on a scale from 0 to 12 . Each score was divided in two categories based on the median, low vs high.

\section{Data analysis}

Descriptive analysis were used to report the sociodemographic characteristics of the study sample (age, level of education, monthly net income, marital status) and other variables of interest such as dyadic efficacy, first pregnancy, teamwork standards, partner interaction, partner smoking status, self-efficacy, anxiety and depressive symptoms, and pregnancy-related anxiety.

We performed a binary logistic regression to identify the factors associated with moderate to high nicotine dependence during pregnancy in our sample. The outcome variable was moderate to high nicotine dependence and the independent variables were: age, level of education, monthly net income, marital status, dyadic efficacy, first pregnancy, teamwork standards, partner interaction, selfefficacy, anxiety and depressive symptoms and pregnancyrelated anxiety, and partner smoking status.

Data analysis was performed with the Statistical Package for the Social Sciences software, SPSS version 23 (SPSS, 2016) and the level of statistical significance chosen was $\mathrm{p}<0.05$. For each explanatory variable missing values were recoded as a new separate category if there were more than 6 missing values. 


\section{Results}

Over $62 \%$ of the pregnant smokers in the sample had moderate to high nicotine dependence. The age of the pregnant smokers ranged from 18 to 42 years, with a mean age of 28.38 and a SD of 7.14 (Table 1). Over half of the participants $(51.6 \%)$ were married.

Table 1: Descriptive statistics on the variables of interest

\begin{tabular}{|c|c|c|c|}
\hline \multicolumn{4}{|c|}{ A. Categorical variables } \\
\hline Variable & Categories & $N$ & $\%$ \\
\hline $\begin{array}{l}\text { Nicotine } \\
\text { dependence }\end{array}$ & $\begin{array}{l}\text { Low nicotine } \\
\text { dependence } \\
\text { Moderate to high } \\
\text { nicotine dependence }\end{array}$ & $\begin{array}{l}48 \\
79\end{array}$ & $\begin{array}{l}37.8 \% \\
62.2 \%\end{array}$ \\
\hline Age & $\begin{array}{l}<25 \text { years old } \\
26-30 \text { years old } \\
>31 \text { years old }\end{array}$ & $\begin{array}{l}38 \\
36 \\
49\end{array}$ & $\begin{array}{l}29.2 \% \\
27.7 \% \\
37.7 \%\end{array}$ \\
\hline $\begin{array}{l}\text { Marital } \\
\text { status }\end{array}$ & $\begin{array}{l}\text { Married } \\
\text { Not married but } \\
\text { living with a stable } \\
\text { partner }\end{array}$ & 66 & $51.6 \%$ \\
\hline Education & $\begin{array}{l}\text { High school or less } \\
\text { College or more }\end{array}$ & $\begin{array}{l}73 \\
53\end{array}$ & $\begin{array}{l}57.9 \% \\
42.1 \%\end{array}$ \\
\hline $\begin{array}{l}\text { Monthly net } \\
\text { income }\end{array}$ & $\begin{array}{l}<633.57 € \\
>633.78 €\end{array}$ & $\begin{array}{l}70 \\
54\end{array}$ & $\begin{array}{l}56.5 \% \\
43.5 \%\end{array}$ \\
\hline $\begin{array}{l}\text { First } \\
\text { pregnancy }\end{array}$ & $\begin{array}{l}\text { Yes } \\
\text { No }\end{array}$ & $\begin{array}{l}71 \\
56\end{array}$ & $\begin{array}{l}55.9 \% \\
44.1 \%\end{array}$ \\
\hline $\begin{array}{l}\text { Partner } \\
\text { smoking }\end{array}$ & $\begin{array}{l}\text { Yes } \\
\text { No }\end{array}$ & $\begin{array}{l}93 \\
36\end{array}$ & $\begin{array}{l}72.1 \% \\
27.9 \%\end{array}$ \\
\hline $\begin{array}{l}\text { Anxiety and } \\
\text { depression } \\
\text { (PHQ-4) }\end{array}$ & $\begin{array}{l}\text { Normal } \\
\text { Mild } \\
\text { Moderate to severe }\end{array}$ & $\begin{array}{l}15 \\
49 \\
57\end{array}$ & $\begin{array}{l}12.4 \% \\
40.5 \% \\
47.1 \%\end{array}$ \\
\hline
\end{tabular}

\section{B. Continuous variables}

\begin{tabular}{lccl} 
Variable name & Mean & Range & SD \\
Pregnancy-related anxiety & 21.18 & $10-39$ & 6.792 \\
General self-efficacy & 28.75 & $17-40$ & 6.328 \\
Teamwork standards & 6.94 & $1-10$ & 3.166 \\
Dyadic efficacy & 69.00 & $3-100$ & 22.80 \\
Negative partner & & & \\
interaction & 7.28 & $0-12$ & 2.15 \\
Positive partner interaction & 8.05 & $0-12$ & 3.40 \\
\hline
\end{tabular}

Women older than 31 years old had higher odds to have moderate to high nicotine dependence in comparison with their younger counterparts (OR=11, C.I 95\%: 2.268$49.104, \mathrm{p}=.003$ ). Women who had a prior pregnancy had lower odds of moderate to high nicotine dependence compared with women who had previous no pregnancies $(\mathrm{OR}=.22$, C.I 95\%: .070-.718, $\mathrm{p}=.012)$. In addition, our findings showed that pregnant women with a negative screen of anxiety and depressive symptoms had higher odds of moderate to high nicotine dependence $(\mathrm{OR}=.19$, C.I 95\%: .037-.973, $\mathrm{p}=.046$ ). Furthermore, pregnant women who experienced negative partner interactions had higher odds of moderate to high nicotine dependence $(\mathrm{OR}=2.55$, C.I $95 \%: 1.055-6.197, \mathrm{p}=.038)$.
Table 2: Multiple logistic regression results: moderate to high nicotine dependence (vs low nicotine dependence)

\begin{tabular}{|c|c|c|}
\hline $\begin{array}{l}\text { Outcome: moderate to high } \\
\text { nicotine dependence }\end{array}$ & $\boldsymbol{O R}^{a}$ & $\begin{array}{l}\text { 95\% C.I. } \\
\text { Lower } \\
\text { Upper }\end{array}$ \\
\hline $\begin{array}{l}26-30 \text { years old }(v s<=\text { less } \\
\text { than } 25 \text { years old })\end{array}$ & 2.65 & $.790-8.948$ \\
\hline More than 31 years old & $10.55^{*}$ & $2.268-49.104$ \\
\hline $\begin{array}{l}\text { Not married but living with a } \\
\text { partner (vs }<=\text { married) }\end{array}$ & .38 & $.134-1.087$ \\
\hline $\begin{array}{l}\text { College education or higher } \\
\text { (vs }<=\text { highschool or less) }\end{array}$ & .87 & $.242-3.108$ \\
\hline $\begin{array}{l}\text { More than } 633.78 € \text { monthly } \\
\text { net income (vs }<=\text { less than } \\
633.57 €)\end{array}$ & .77 & $.230-2.565$ \\
\hline $\begin{array}{l}\text { Not the first pregnancy }(<= \\
\text { first pregnancy) }\end{array}$ & $.22 *$ & $.070-.718$ \\
\hline $\begin{array}{l}\text { Not having a smoker partner } \\
(<=\text { smoker partner })\end{array}$ & .28 & $.763-10.440$ \\
\hline $\begin{array}{l}\text { Mild anxiety and depressive } \\
\text { symptoms (vs }<=\text { normal) }\end{array}$ & $.19^{*}$ & $.037-.973$ \\
\hline $\begin{array}{l}\text { Moderate to severe anxiety } \\
\text { and depressive symptoms }\end{array}$ & .54 & $.104-2.774$ \\
\hline $\begin{array}{l}\text { High dyadic efficacy score } \\
\text { (vs }<=\text { low dyadic efficacy } \\
\text { score) }\end{array}$ & 2.07 & $.695-6.175$ \\
\hline $\begin{array}{l}\text { High anxiety related to } \\
\text { pregnancy score }(\mathrm{vs}<=10 \mathrm{w} \\
\text { anxiety related to pregnancy } \\
\text { score })\end{array}$ & 1.60 & $.547-4.709$ \\
\hline $\begin{array}{l}\text { High general self-efficacy } \\
\text { score (vs<=low general self- } \\
\text { efficacy score) }\end{array}$ & .43 & $.147-1.257$ \\
\hline $\begin{array}{l}\text { High negative partner } \\
\text { interaction }(\mathrm{vs}<=\text { low negative } \\
\text { partner interaction) }\end{array}$ & $2.55^{*}$ & $1.055-6.197$ \\
\hline $\begin{array}{l}\text { High positive partner } \\
\text { interaction (vs }<=\text { low positive } \\
\text { partner interaction) }\end{array}$ & .70 & $.237-2.045$ \\
\hline Notes: ${ }^{a}$ OR: odds ratios; ${ }^{b}$ CI: c & enc & val \\
\hline
\end{tabular}

This research paper aimed to identify possible factors that could be associated with moderate to high nicotine dependence in pregnant women from a Romanian sample. Older age, first pregnancy, a negative screen for anxiety and depression, and negative partner interactions related to smoking were significantly correlated with increased odds of moderate-to-high nicotine dependence during pregnancy. In addition, high dyadic efficacy, low selfefficacy, high pregnancy-related anxiety, and a nonsmoking life partner were correlated with increased odds of moderate to high nicotine dependence, although the results did not reach statistical significance.

Older women are more prone to nicotine dependence during pregnancy. One factor involved in this association could be that these women are smoking for a long time. Being older smokers, women have a longer history and more experiences with smoking and are more likely to have strong nicotine dependence. Also, there are certain obstacles to quitting at an older age, such as thinking that smoking only a few cigarettes does not make any harm or 
that there are no benefits of quitting at this age (Donze, Ruffieux, \& Cornuz, 2006). Even though in some previous studies the smoking prevalence of older women was lower compared to teenage smoker mothers, the older mothers smoked heavier than young mothers (Mohsin \& Bauman, 2005b). It is also important to note the age of smoking onset, because an earlier onset of smoking is a predictor for continued smoking during pregnancy (Chen, Stanton, \& Li, 2006).

First time pregnant women had increased odds of moderate to high nicotine dependence compared with women who had no previous pregnancies. Part of the explanation is that pregnancy is a new and stressful period accompanied by many changes and smoking may be a way of coping with pregnancy-related anxiety (Van Der, Pim, Gouke, \& Bonsel, 2009) Also, quitting smoking would be a stress itself because it implies effort and energy resources for managing immediate consequences of quitting smoking and maintaining smoking cessation at least for the period of pregnancy. On the other hand, first-time pregnant women may lack information about the health consequences of their future baby if they smoke during pregnancy. In this regard, smoking cessation programs and treatments are very important and helpful because this vulnerable population may lack either valuable information about maternal smoking, either the skills to quit smoking or both (Higgins, 2002). There is also the concept of "spontaneous quitting" that refers to women who manage to quit smoking on their own when they found out about the pregnancy. This is a subject that deserves more attention and research on the specific personality, cognitive, behavioral, motivational factors that differentiate these women from the ones who continue to smoke even though they are aware of their pregnancy (Solomon \& Quinn, 2004).

Although some studies found that negative partner interactions related to smoking did not predict the woman's smoking cessation, our finding suggest a positive correlation with increased odds of moderate-to-high nicotine dependence during pregnancy. This could indicate that the smoking behavior of highly addicted pregnant smokers (i.e. high number of daily cigarettes or short time to first cigarette in the morning) draw more frequent negative partner support behaviors. Conversely, it could mean that negative partner support behaviors drive pregnant women towards increased nicotine dependence (Burns, Rothman, Fu, Lindgren, \& Joseph, 2014).

Most studies found self-efficacy to be positively correlated with smoking cessation. One of them states that high self-efficacy was associated with smoking cessation and that assessing self-efficacy is very important for predicting if a woman will cease smoking during pregnancy and if she will maintain smoking cessation in the next years (Lindberg et al., 2015). Self-efficacy can contribute to treatment for smoking cessation, being valued as one of the most important cognitive factors in smoking during pregnancy because it promotes behavioral change, influencing a person's intentions, effort and persistence (Reeve, 2016).

Taking into consideration the health problems that the future baby is exposed to by maternal smoking, there is a constant need to promote smoking cessation to as many pregnant women as possible. This process can be accomplished through primary care and maternity care settings (Lumley, Chamberlain, \& Dowswell, 2009). Both doctors and nurses can be involved in smoking evaluation and quitting programs (Gebauer, Kwo, Haynes, \& Wewers,
1998). There is also a need for help from a mental health specialist, if the future mother lives with high levels of stress or is facing anxiety or depression related to pregnancy and smoking.

One of the study's limitations was that it couldn't determine causal effects of the variables of interest because the study relied on cross-sectional data. An additional limitation was the relatively small sample size. However, our logistic regression model correctly predicts close to $77 \%$ of the nicotine dependence binary values, including close to $88 \%$ of the moderate to high nicotine dependent women. Complete classification results are available from the authors.

\section{Conclusion}

This paper contributed to identifying or clarifying which factors were associated with moderate to high nicotine dependence in a sample of pregnant women from Romania and is valuable for approaching smoking cessation in pregnancy through different programs. Older age, first pregnancy, a negative screen for anxiety and depression, and negative partner interactions related to smoking were significantly correlated with increased odds of moderate-to-high nicotine dependence during pregnancy. Once the level nicotine dependence is established, cessation treatment should target specific risks that are associated with this dependence. Maternal risk factors, spousal smoking status, and interactions in the couple hold promise in future tobacco cessation interventions. Future research should focus on both the prenatal smoking cessation and on postnatal relapse prevention among highly dependent women.

\section{Acknowledgments}

This article is a result of a special scholarship for scientific activity provided by Babes-Bolyai University, Cluj-Napoca, Romania. Research reported in this article was supported by the coordinator of this scholarship, Adriana Băban, PhD. Funding was also provided, in part, by the Fogarty International Center of the National Institutes of Health under award K01TW009654. Partial support was also received (Cristian Ioan Meghea and Oana Maria Blaga) under award R21TW010896. The content is solely the responsibility of the authors and does not necessarily represent the official views of the National Institutes of Health.

\section{References}

Borland, R., Yong, H.-H., O'Connor, R. J., Hyland, A., \& Thompson, M. E. (2010). The reliability and predictive validity of the Heaviness of Smoking Index and its two components: findings from the International Tobacco Control Four Country study. Nicotine \& Tobacco Research: Official Journal of the Society for Research on Nicotine and Tobacco, 12 Suppl(Suppl 1), S45-50. doi: 10.1093/ntr/ntq038

Burns, R. J., Rothman, A. J., Fu, S. S., Lindgren, B., \& Joseph, A. M. (2014). The Relation between Social Support and Smoking Cessation: Revisiting an Established Measure to Improve Prediction. Annals of Behavioral Medicine: A Publication of the Society of Behavioral Medicine, 47(3), 369. doi: 10.1007/S12160-013-9558-7

Chaiton, M. O., Cohen, J. E., McDonald, P. W., \& Bondy, S. J. (2007). The Heaviness of Smoking Index as a predictor of smoking cessation in Canada. Addictive Behaviors, 32(5), 1031-1042. doi: 10.1016/j.addbeh.2006.07.008 
Chen, X., Stanton, B., \& Li, X. (2006). Age of Smoking Onset as a Predictor of Smoking Cessation During Pregnancy. Retrieved https://www.researchgate.net/publication/7070180

Cnattingius, S. (2004). The epidemiology of smoking during pregnancy: Smoking prevalence, maternal characteristics, and pregnancy outcomes. Nicotine \& Tobacco Research, 6, 125-140. doi: 10.1080/14622200410001669187

Cohen, S., \& Lichtenstein, E. (1990). Partner behaviors that support quitting smoking. Journal of Consulting and Clinical. Retrieved from http://psycnet.apa.org/journals/ccp/58/3/304/

DiFranza, J. R., \& Lew, R. A. (1995). Effect of maternal cigarette smoking on pregnancy complications and sudden infant death syndrome. The Journal of Family Practice, 40(4), 385-394. Retrieved from http://www.ncbi.nlm.nih.gov/pubmed/7699353

Donze, J., Ruffieux, C., \& Cornuz, J. (2006). Determinants of smoking and cessation in older women. Age and Ageing, 36(1), 53-57. doi: 10.1093/ageing/afl120

Etter, J. F., Duc, T. V, \& Perneger, T. V. (1999). Validity of the Fagerström test for nicotine dependence and of the Heaviness of Smoking Index among relatively light smokers. Addiction (Abingdon, England), 94(2), 269-281. Retrieved from http://www.ncbi.nlm.nih.gov/pubmed/10396794

Flick, L. H., Cook, C. A., Homan, S. M., McSweeney, M., Campbell, C., \& Parnell, L. (2006). Persistent Tobacco Use During Pregnancy and the Likelihood of Psychiatric Disorders. American Journal of Public Health, 96(10), 1799-1807. doi: 10.2105/AJPH.2004.057851

Gebauer, C., Kwo, C.-Y., Haynes, E. F., \& Wewers, M. E. (1998). A Nurse-Managed Smoking Cessation Intervention During Pregnancy (Vol. 27). doi: 10.1111/j.15526909.1998.tb02590.x

Graham, H., Hawkins, S. S., \& Law, C. (2010). Lifecourse influences on women's smoking before, during and after pregnancy. Social Science \& Medicine, 70(4), 582-587. doi: 10.1016/j.socscimed.2009.10.041

Hayashi, K., Matsuda, Y., Kawamichi, Y., Shiozaki, A., \& Saito, S. (2011). Smoking during pregnancy increases risks of various obstetric complications: a case-cohort study of the Japan Perinatal Registry Network database. Journal of Epidemiology, 21(1), 61-66. doi: $10.2188 /$ jea.je20100092

Heatherton, T. F., Kozlowski, L. T., Frecker, R. C., \& Fagerström, K. O. (1991). The Fagerström Test for Nicotine Dependence: a revision of the Fagerström Tolerance Questionnaire. British Journal of Addiction, 86(9), 1119-1127. Retrieved from http://www.ncbi.nlm.nih.gov/pubmed/1932883

Heatherton, T. F., Kozlowski, L. T., Frecker, R. C., Rickert, W., \& Robinson, J. (1989). Measuring the heaviness of smoking: using self-reported time to the first cigarette of the day and number of cigarettes smoked per day. British Journal of Addiction, 84(7), 791-799. Retrieved from http://www.ncbi.nlm.nih.gov/pubmed/2758152

Hellerstedt, W. L., Pirie, P. L., Lando, H. A., Curry, S. J., McBride, C. M., Grothaus, L. C., \& Nelson, J. C. (2011). Differences in preconceptional and prenatal behaviors in women with intended and unintended pregnancies. Doi: 10.2105/AJPH.88.4.663. doi: 10.2105/AJPH.88.4.663

Higgins, S. (2002). Smoking in pregnancy. Current Opinion in Obstetrics and Gynecology (Vol. 14). Retrieved from https://pdfs.semanticscholar.org/c80d/c5562657f1 1 ff0845 707777084b9c948c93f.pdf

Huizink, A. C., Mulder, E. J. H., Robles De Medina, P. G., Visser, G. H. A., \& Buitelaar, J. K. (2004). Is pregnancy anxiety a distinctive syndrome? Early Human Development, 79(2), 81-91. doi: 10.1016/j.earlhumdev.2004.04.014
John, U., Meyer, C., Schumann, A., Hapke, U., Rumpf, H. J., Adam, C., ... Lüdemann, J. (2004). A short form of the Fagerström Test for Nicotine Dependence and the Heaviness of Smoking Index in two adult population samples. Addictive Behaviors, 29(6), 1207-1212. doi: 10.1016/j.addbeh.2004.03.019

Ko, T.-J., Tsai, L.-Y., Chu, L.-C., Yeh, S.-J., Leung, C., Chen, C.-Y., ... Hsieh, W.-S. (2014). Parental Smoking During Pregnancy and Its Association with Low Birth Weight, Small for Gestational Age, and Preterm Birth Offspring: A Birth Cohort Study. Pediatrics \& Neonatology, 55(1), 20-27. doi: 10.1016/j.pedneo.2013.05.005

Kroenke, K., Spitzer, R. L., Williams, J. B. W., \& Lowe, B. (2009). An Ultra-Brief Screening Scale for Anxiety and Depression: The PHQ-4. Psychosomatics, 50(6), 613-621. doi: 10.1176/appi.psy.50.6.613

Lindberg, A., Niska, B., Stridsman, C., Eklund, B.-M., Eriksson, B., \& Hedman, L. (2015). Low nicotine dependence and high self-efficacy can predict smoking cessation independent of the presence of chronic obstructive pulmonary disease: a three year follow up of a population-based study. Tobacco Induced Diseases, 13(1), 27. doi: 10.1186/s12971-015-0055-6

Little, J., Cardy, A., \& Munger, R. G. (2004). Tobacco smoking and oral clefts: a meta-analysis. Bulletin of the World Health Organization, 82(3), 213-218. Retrieved from http://www.ncbi.nlm.nih.gov/pubmed/15112010

Lumley, J., Chamberlain, C., \& Dowswell, T. (2009). Interventions for promoting smoking cessation during pregnancy. Database Syst Rev. Retrieved from http://onlinelibrary.wiley.com/doi/10.1002/14651858.CD0 01055.pub3/full

Meghea, C. I., Rus, I. A., \& Rus, D. (2012a). Risk factors associated with nicotine dependence in a sample of Romanian pregnant smokers. European Journal of Obstetrics \& Gynecology and Reproductive Biology, 163(1), 22-26. doi: 10.1016/j.ejogrb.2012.03.033

Meghea, C. I., Rus, I. A., \& Rus, D. (2012b). Risk factors associated with nicotine dependence in a sample of Romanian pregnant smokers. European Journal of Obstetrics \& Gynecology and Reproductive Biology, 163(1), 22-26. doi: 10.1016/j.ejogrb.2012.03.033

Melvin, C., \& Gaffney, C. (2004). Treating nicotine use and dependence of pregnant and parenting smokers: An update. Nicotine \& Tobacco Research, 6, 107-124. doi: $10.1080 / 14622200410001669231$

Ministerul Sanatatii. (2018). Studiul global privind consumul de tutun la adulti (Romania).

Mohsin, M., \& Bauman, A. E. (2005a). Socio-demographic factors associated with smoking and smoking cessation among 426,344 pregnant women in New South Wales, Australia. BMC Public Health, 5(1), 138. doi: 10.1186/1471-2458-5-138

Mohsin, M., \& Bauman, A. E. (2005b). Socio-demographic factors associated with smoking and smoking cessation among 426,344 pregnant women in New South Wales, Australia. BMC Public Health, 5(1), 138. doi: 10.1186/1471-2458-5-138

Mund, M., Louwen, F., Klingelhoefer, D., \& Gerber, A. (2013). Smoking and Pregnancy - A Review on the First Major Environmental Risk Factor of the Unborn. International Journal of Environmental Research and Public Health, 10(12), 6485-6499. doi: $10.3390 /$ ijerph 10126485

Nur, N. (2017). Association of risk factors with smoking during pregnancy among women of childbearing age: an epidemiological field study in Turkey. Sao Paulo Medical Journal, 135(2), 100-106. doi: 10.1590/15163180.2016.021921102016

Nur, N., \& Nur, N. (2017). Association of risk factors with smoking during pregnancy among women of childbearing 
age: an epidemiological field study in Turkey. Sao Paulo Medical Journal, 135(2), 100-106. doi: 10.1590/15163180.2016.021921102016

Panaretto, K. S., Mitchell, M. R., Anderson, L., Gilligan, C., Buettner, P., Larkins, S. L., \& Eades, S. (2009). Tobacco use and measuring nicotine dependence among urban Indigenous pregnant women. The Medical Journal of Australia, 191(10), 554-557. doi: 10.5694/J.13265377.2009.TB03309.X

Passey, M. E., Sanson-Fisher, R. W., D’Este, C. A., \& Stirling, J. M. (2014). Tobacco, alcohol and cannabis use during pregnancy: Clustering of risks. Drug and Alcohol Dependence, $\quad 134, \quad 44-50 . \quad$ doi: 10.1016/j.drugalcdep.2013.09.008

Reeve, T. A. (2016). A comparison of self-efficacy between pregnant women who use cigarettes versus electronic nicotine delivery systems: A cross-sectional study of participants in the BC Healthy Connections Project. Retrieved from http://summit.sfu.ca/item/16980

Rodriguez, D. (2019). Cigarette smoking in pregnancy: Cessation strategies and treatment options - UpToDate. Retrieved

from https://www.uptodate.com/contents/cigarette-smoking-inpregnancy-cessation-strategies-and-treatment-options

Schneider, S., \& Schütz, J. (2008). Who smokes during pregnancy? A systematic literature review of populationbased surveys conducted in developed countries between 1997 and 2006. The European Journal of Contraception \& Reproductive Health Care, 13(2), 138-147. doi: 10.1080/13625180802027993

Širvinskienė, G., Žemaitienė, N., Jusienė, R., Šmigelskas, K., Veryga, A., \& Markūnienè, E. (2016). Smoking during pregnancy in association with maternal emotional wellbeing. Medicina, 52(2), 132-138. doi: 10.1016/j.medici.2016.02.003

Solomon, L. J., \& Quinn, V. P. (2004). Spontaneous quitting: Self-initiated smoking cessation in early pregnancy. doi: 10.1080/14622200410001669132

SPSS. (2016). IBM SPSS Statistics 23 Part 1: Descriptive Statistics. Retrieved from https://www.calstatela.edu/sites/default/files/groups/Infor mation Technology Services/training/pdf/spss23p1.pdf

Sterba, K. R., Rabius, V., Carpenter, M. J., Villars, P., Wiatrek, D., \& McAlister, A. (2011a). Dyadic Efficacy for Smoking Cessation: Preliminary Assessment of a New Instrument. Nicotine \& Tobacco Research, 13(3), 194201. doi: $10.1093 / \mathrm{ntr} / \mathrm{ntq} 236$

Sterba, K. R., Rabius, V., Carpenter, M. J., Villars, P., Wiatrek, D., \& McAlister, A. (2011b). Dyadic Efficacy for Smoking Cessation: Preliminary Assessment of a New Instrument. Nicotine \& Tobacco Research, 13(3), 194 201. doi: $10.1093 / \mathrm{ntr} / \mathrm{ntq} 236$

Tsai, J., Edens, E. L., \& Rosenheck, R. A. (2011). Nicotine dependence and its risk factors among users of veterans health services, 2008-2009. Preventing Chronic Disease, 8(6), A127. Retrieved from http://www.ncbi.nlm.nih.gov/pubmed/22005620

Van Der, M. F., Pim, W., Gouke, C., \& Bonsel, J. (2009). Psychosocial problems and continued smoking during pregnancy. Short Communication. Addictive Behaviors (Vol. 34). Retrieved from https://pure.uva.nl/ws/files/1306618/80160 07.pdf 